\title{
THE PROFILE OF RISK FACTORS AND IN-PATIENT OUTCOMES OF STROKE IN KUMASI, GHANA
}

\author{
F. S. SARFO ${ }^{1,2}$, J. W. ACHEAMPONG ${ }^{1,2}$, L. T. APPIAH ${ }^{1}$, E. OPAREBEA ${ }^{1}$, A. AKPALU ${ }^{3}$ and \\ G. BEDU-ADDO ${ }^{1,2}$ \\ ${ }^{1}$ Komfo Anokye Teaching Hospital, Kumasi, Ghana, ${ }^{2}$ School of Medical Sciences, Kwame Nkrumah Universi- \\ ty of Science and Technology, Kumasi, Ghana, ${ }^{3}$ Korle Bu Teaching Hospital, Korle-Bu, Accra, Ghana
}

DOI: http://dx.doi.org/10.4314/gmj.v48i3.3

Corresponding Author: Dr. Fred Stephen Sarfo

Email: Stephensarfo78@gmail.com

Conflict of Interest: None declared

\section{SUMMARY}

Background: Stroke is an emerging public health challenge in Ghana requiring urgent attention for its control. Because some of the risk factors for stroke are modifiable, characterisation of these risk factors in the Ghanaian population as well as outcomes of stroke are urgently needed to guide policy for non-communicable diseases. We therefore conducted this study to evaluate the frequencies of the traditional risk factors and outcomes of stroke at the main tertiary referral centre in the middle belt of Ghana in a prospective observational study.

Methods and results: Patients with a clinical diagnosis of stroke were consecutively recruited and vascular risk factors were assessed as well as markers of severity of stroke and in-patient treatment outcomes. 265 patients were recruited, $56.6 \%$ were females and mean \pm SD age of $64.6 \pm 14.54$ years. $85 \%, 73 \%$ and $58 \%$ of patients had systemic arterial hypertension, physical inactivity and obesity respectively as common risk factors. We identified that patients with stroke had a median of 3 traditional risk factors, were unaware of the presence of these risk factors or were poorly controlled if known. Stroke was associated with a high inpatient case fatality rate of $43 \%$ principally among patients with haemorrhagic stroke.

Conclusions: Our findings indicate that urgent concerted efforts are required to improve public awareness and management of the prevailing risk factors of stroke in Ghana.

Key words: Stroke, risk factors, mortality, Ghana

\section{INTRODUCTION}

Stroke is the third leading cause of mortality worldwide and global estimates of disease burden projects that within the next two decades it will continue to rank among the top four causes of death even within developing countries. ${ }^{1}$ A review of stroke epidemiology over the last four decades has suggested that while the inci- dence of stroke is on the decline in most developed countries through improved awareness and management of risk factors, that of developing countries continues to increase with a nearly $100 \%$ increment for some low-income countries. ${ }^{2}$ Furthermore nearly twothirds of stroke case fatalities occur in resource-limited settings where infrastructure is lacking to provide the requisite support for stroke patients.

Because the annual cost of stroke -amounting to some $\$ 65.5$ billion in 2008 in the US alone ${ }^{3}$ is beyond the reach of most developing countries, whose limited health resources are being stretched to meet the health needs imposed by infections such as malaria, HIV and tuberculosis, there is an urgent need for attention to be focused on the prevention of the catastrophic consequences of vascular diseases such as stroke. Among the secondary prevention strategies for stroke advocated by the World Health Organisation, emphasis is placed on intensified reduction in exposure to major cardiovascular risk factors. ${ }^{4}$

However because the prevalence and characterisation of stroke risk factors in most Sub-Saharan countries such as Ghana remains largely unknown, resource allocation and strategic planning for prevention continues to be met with difficulties. Thus in the present study we describe the profile of risk factors, clinical types and characterise the factors associated with stroke inpatient mortality at Komfo Anokye Teaching Hospital, the second largest tertiary referral centre in Ghana.

\section{METHODS}

Ethics statement: The study was approved by and conformed to the ethical guidelines of the Committee on Human Research Publications and Ethics of the School of Medical Sciences of the Kwame Nkrumah University of Science and Technology and the Komfo Anokye Teaching Hospital, ref number: CHRPE/01/10. 
After a thorough explanation of the research protocol in the local dialect, written informed consent was obtained either from conscious patients or their firstdegree relatives for patients with depressed level of consciousness by signing or thumb-printing depending on literacy status.

This study was an observational prospective study where consecutive patients aged $>15$ years with a case definition of stroke were eligible for enrollment. The minimum criteria for a definite or probable stroke diagnosis include evidence of sudden or rapid onset of neurological symptoms lasting $>24$ hours or leading to death in the absence of evidence for a non-stroke cause according to the WHO clinical definition of stroke. ${ }^{6}$ Patient's socio-demographic information, history and clinical examination findings with emphasis on cardiovascular risk factors for stroke and outcomes were captured on a study questionnaire. Routine haematology and fasting biochemistry were performed within 48 hours of admission.

The following definitions and techniques were used to identify risk factors for stroke in each patient:

1. Hypertension was defined as systolic blood pressure $\geq 140 \mathrm{~mm} \mathrm{Hg}$ or diastolic pressure $\geq$ $90 \mathrm{~mm} \mathrm{Hg}$ persisting $>7$ days after the acute event (World Health Organization classification) or pre-stroke treatment with antihypertensive drugs. ${ }^{7}$

2. Diabetes mellitus was defined as a previous diagnosis of type I or II diabetes, at least 2 random blood glucose readings of $\geq 11.1$ $\mathrm{mmol} / \mathrm{l}$, or a fasting blood glucose reading of $\geq 7 \mathrm{mmol} / \mathrm{l}$ after the acute phase of stroke to exclude acute transient elevation of glucose as a stress response after stroke. ${ }^{8}$

3. Hypercholesterolemia was defined as serum cholesterol of $>5.2 \mathrm{mmol} / 1$ or pre-stroke treatment with a cholesterol-lowering agent. ${ }^{9}$

4. Raised body mass index was defined as $>27$ $\mathrm{kg} / \mathrm{m}^{2}$ in ambulant patients or waist circumference of $>80 \mathrm{~cm}$ in females and $>94 \mathrm{~cm}$ in males. Waist circumference was measured by using a tape measure horizontally placed at the level of the superior crests and ensuring that the tape measure was snug and did not compress the skin. Measurement was made at the end of normal expiration. ${ }^{10}$

5. Current smoking status and alcohol intake status was ascertained from either the patient or a reliable relative. A high alcohol intake was defined as $\geq 14 \mathrm{U}$ per week for women, $\geq 21 \mathrm{U}$ per week for men.
6. An ECG and/or an echocardiogram were performed in patients with suspected cardioembolic stroke.

7. Physical activity status of participants was assessed using the International Physical Activity Questionnaire. For participants who were either aphasic or unconscious their relatives were questioned on patients' physical activity status. Responders who reported spending more than half the day on their feet or were involved in daily exercises were classified as physically active. Those who spent less than half of the day on their feet or led a sedentary life were classed as physically inactive as has previously been applied. ${ }^{10}$

The classification of the pathologic type of stroke into cerebral ischaemia or primary intracerebral haemorrhage was based on results from brain imaging with a computed tomography scan or the Siriraj stroke score. ${ }^{11}$ The validity of the Siriraj stroke score was assessed by determining its sensitivity, specificity and positive predictive accuracy among patients who had CT scan of the brain performed.

The National Institute of Health Stroke Scale was employed to determine the severity of stroke within $24 \mathrm{~h}$ of admission. Patient autonomy and functional status before the onset of stroke were assessed with a modified Barthel Scale of Activities of Daily Living (m-ADL). The modification involved the replacement of "the ability to walk up and down stairs" with "the ability to reach household facilities in separate buildings". The m-ADL scale was used retrospectively to document possible pre-stroke disabilities, and the Rankin Disability Score was used to assess the functional status of stroke patients on the day of discharge.

Statistical analysis: The data from the questionnaire were entered into a Microsoft excel (2003) sheet. Descriptive results of demographics and identifiable risk factors were presented as percentages. The student's ttest and the Mann-Whitney U-test were used to compare means and medians respectively while the Fisher's exact test was used to test for significance between observed associations. Associations between risk of death and clinical and laboratory parameters were analyzed using a multiple logistic regression modeling. In all analyses, a 2-tailed p-value less than 0.05 were considered significant. Statistical analyses were performed using the Graph Pad Prism 4 and multiple logistic regressions were performed using SPSS version 17. 


\section{RESULTS}

Demographic, clinical and diagnostic data:

A total of 265 consecutive patients with clinical diagnosis of stroke were recruited. This included 115 males and 150 females with a slight preponderance of females with a female to male ratio of approximately 1.3:1.0. The mean \pm SD age of study participants was $64.6 \pm 14.54$ years with a modal age range of $70-79$ years. Approximately $60 \%$ of patients presented within 24 hours after onset of stroke for management with the rest presenting within $2-14$ days. $41 \%$ had right-sided weakness, 35\% had left-sided weakness, $23 \%$ had bilateral weakness while $1 \%$ had no motor weakness. The frequencies of other symptoms accompanying focal motor neurological deficit in study subjects were loss of speech (56\%), depressed level of consciousness $(44 \%)$, headaches $(26 \%)$, seizures $(9 \%)$, vomiting $(8 \%)$ and a few presented with dizziness, palpitations, fever, restlessness or neck pains.

Using the Siriraj stroke scoring scale, $43 \%$ of participants were classified as having ischaemic stroke, 39\% had haemorrhagic stroke and $18 \%$ were equivocal. Of the 19 cranial CT scans performed in this study 10 patients had ischaemic strokes while the remainder had haemorrhagic strokes. In order to ascertain the accuracy of the Siriraj stroke score that was used to classify stroke type in a majority of study participants, the clinical scoring scale was compared with CT scan results. This analysis revealed that all 10 lesions classified as ischaemic by the Siriraj stroke scale were subsequently confirmed on CT-scan. Furthermore 6 patients who had haemorrhagic stroke by the Siriraj stroke score were also found to have haemorrhagic strokes on CT scan but 3 patients with equivocal scores on the Siriraj stroke scoring scale had haemorrhagic strokes on CT scan. Thus the Siriraj stroke scoring scale had a sensitivity of $100 \%$, a specificity of $100 \%$ and positive predictive accuracy of $100 \%$ for cerebral infarction while that for intracerebral haemorrhage were $67 \%, 60 \%$ and $100 \%$ respectively.

The severity of stroke at presentation as assessed using the National Institute of Health Stroke Scale revealed a median (range) score of 16 (2-42). Finally the functional status of patients before the onset of stroke was measured with the modified Barthel's scale which showed a median score of $20 / 20$ with a range of $6 / 20-$ 20/20).

Traditional vascular risk factors of stroke: Systemic hypertension was the preponderant modifiable risk factor identified in $85 \%$ of stroke patients followed by physical inactivity (73\%), obesity (58\%), hypercholesterolemia (47\%) and type 2 diabetes mellitus (38\%) as shown in Table 1. Fifty-nine percent (59\%), 15\% and $1 \%$ of participants were aware of the presence of hypertension, diabetes mellitus and dyslipidaemia respectively prior to the onset of stroke. Among patients with an awareness of the presence of vascular risk factors especially hypertension, $35 \%$ admitted to compliance with their medications, $52 \%$ were not compliant while compliance could not be assessed in $13 \%$ of study participants $(n=175)$. Reasons cited by stroke patients for their non-compliance included the use of herbal remedies for cure of their vascular risk factors (59\%), financial constraints $(12 \%)$ while $22 \%$ gave no reasons but the remainder reported frequent travels, side effects of medications and the belief that they have been cured of hypertension after initial treatment with antihypertensive.

Hypercholesterolemia and obesity were significantly more prevalent among female subjects than male subjects. Conversely male subjects were more significantly predisposed to heavy alcohol consumption and cigarette smoking compared with female participants as shown in Table 1 . Only $6 \%$ of strokes were attributable to probable cardio-embolic causes. Figure 1 depicts the risk factor profile per subject. The median cumulative number of modifiable traditional risk factors of stroke per patient was $3(0-6)$.

Table 1 The percentage frequency of the traditional risk factors of stroke among study subjects

\begin{tabular}{|l|l|l|l|l|}
\hline Risk factor & $\begin{array}{l}\text { Male \% } \\
(\mathbf{n = 1 1 5})\end{array}$ & $\begin{array}{l}\text { Female } \\
\mathbf{\%}(\mathbf{n}=\mathbf{1 5 0})\end{array}$ & $\begin{array}{l}\boldsymbol{P} \\
\text { value }\end{array}$ & $\begin{array}{l}\text { Overall } \\
\text { prevalence } \\
\mathbf{\%}(\mathbf{n}=\mathbf{2 6 5})\end{array}$ \\
\hline Hypertension & 81 & 88 & 0.12 & 85 \\
\hline Physical inactivity & 70 & 76 & 0.13 & 73 \\
\hline Obesity & 33 & 76 & 0.0001 & 58 \\
\hline $\begin{array}{l}\text { Hypercholesterole- } \\
\text { mia }\end{array}$ & 33 & 58 & 0.003 & 47 \\
\hline Diabetes mellitus & 33 & 42 & 0.16 & 38 \\
\hline $\begin{array}{l}\text { Heavy alcohol con- } \\
\text { sumption }\end{array}$ & 34 & 7 & 0.0001 & 19 \\
\hline Previous stroke & 10 & 24 & 0.10 & 14 \\
\hline Cigarette smoking & 16 & 2 & 0.0001 & 8 \\
\hline Atrial fibrillation & 6 & 3 & 0.66 & 4 \\
\hline $\begin{array}{l}\text { Transient ischaemic } \\
\text { attack }\end{array}$ & 1 & 1 & 1.0 & 2 \\
\hline $\begin{array}{l}\text { Congestive cardiac } \\
\text { failure }\end{array}$ & 0 & 1 & 0.51 & 1 \\
\hline $\begin{array}{l}\text { Carotid artery steno- } \\
\text { sis }\end{array}$ & 0 & 1 & 0.26 & 1 \\
\hline $\begin{array}{l}\text { Intra-cardiac mural } \\
\text { thrombus }\end{array}$ & 1 & 0 & 0.43 & 1 \\
\hline
\end{tabular}

The commonest combination of risk factors was hypertension, hypercholesterolemia and physical inactivity. The 3 patients with no modifiable risk factors of stroke were all elderly male subjects. 
ECG was performed in 118 (45\%) study subjects. 77 $(65 \%)$ had evidence of left ventricular hypertrophy according to the Sokolow's criteria.

\section{In-patient outcomes of stroke:}

The median duration of hospitalisation was 6 days [Interquartile range (IQR), 4-9 days; range, 1-42 days]. Overall case fatality during hospitalisation was $43.4 \%$; with fatality for ischaemic stroke being $17.5 \%$ and that for intra-cerebral haemorrhage of $70.2 \%(p=0.0001)$. Death occurred after a median of 5 days (IQR, 2-8 days; range of $1-21$ days). $35 \%$ of those who died had clinical evidence of aspiration pneumonitis.

Table 2 Admission clinical and laboratory findings according to outcome of stroke

\begin{tabular}{|c|c|c|c|}
\hline Variable & $\begin{array}{l}\text { Alive at dis- } \\
\text { charge } \\
\mathrm{N}=150\end{array}$ & $\begin{array}{l}\text { Died on ad- } \\
\text { mission } \\
\mathrm{N}=115\end{array}$ & p-value \\
\hline $\begin{array}{l}\text { Systolic blood } \\
\text { pressure }(\mathrm{mmHg})\end{array}$ & $172.8 \pm 36.17$ & $179.9 \pm 40.75$ & 0.13 \\
\hline $\begin{array}{l}\text { Diastolic blood } \\
\text { pressure }(\mathrm{mmHg})\end{array}$ & $101.2 \pm 20.56$ & $107 \pm 24.52$ & 0.03 \\
\hline $\begin{array}{ll}\text { Pulse } & \text { rate } \\
\text { (beats/min) }\end{array}$ & $84.3 \pm 13.38$ & $89.6 \pm 15.30$ & 0.003 \\
\hline $\begin{array}{l}\text { Glasgow coma } \\
\text { score }\end{array}$ & $15(3-15)$ & $9(3-15)$ & $<0.0001$ \\
\hline NIHSS & $10(2-32)$ & $28(2-42)$ & $<0.0001$ \\
\hline $\begin{array}{l}\text { Blood } \\
(\mathrm{mmol} / \mathrm{l})\end{array}$ & $9.0 \pm 4.93$ & $10.6 \pm 4.02$ & 0.0065 \\
\hline $\begin{array}{l}\text { Total cholesterol } \\
(\mathrm{mmol} / \mathrm{l})\end{array}$ & $5.1 \pm 1.43$ & $5.4 \pm 1.94$ & 0.3 \\
\hline $\begin{array}{l}\text { HDL- cholesterol } \\
(\mathrm{mmol} / \mathrm{l})\end{array}$ & $1.3 \pm 0.60$ & $1.6 \pm 0.88$ & 0.003 \\
\hline $\begin{array}{l}\text { LDL-cholesterol } \\
(\mathrm{mmol} / \mathrm{l})\end{array}$ & $3.4 \pm 1.60$ & $4.0 \pm 2.00$ & 0.09 \\
\hline $\begin{array}{l}\text { Triglycerides } \\
(\mathrm{mmol} / \mathrm{l})\end{array}$ & $1.4 \pm 0.66$ & $1.5 \pm 0.95$ & 0.49 \\
\hline $\begin{array}{l}\text { Creatinine } \\
(\mu \mathrm{mol} / 1)\end{array}$ & $118.9 \pm 130.0$ & $175.9 \pm 234.9$ & 0.02 \\
\hline Urea $(\mathrm{mmol} / \mathrm{l})$ & $7.2 \pm 6.28$ & $11.5 \pm 13.35$ & 0.003 \\
\hline $\begin{array}{ll}\text { Uric } & \text { acid } \\
(\mathrm{mmol} / \mathrm{l}) & \\
\end{array}$ & $403.2 \pm 180.7$ & $545.9 \pm 294.1$ & 0.0004 \\
\hline $\begin{array}{l}\text { Haemoglobin } \\
(\mathrm{g} / \mathrm{dl})\end{array}$ & $13.1 \pm 2.23$ & $13.6 \pm 2.27$ & 0.08 \\
\hline $\begin{array}{l}\text { White cell count } \\
\left(\mathrm{x} 10^{9}\right)\end{array}$ & $8.1 \pm 3.19$ & $11.2 \pm 4.84$ & $<0.0001$ \\
\hline $\begin{array}{l}\text { Platelet count (x } \\
\left.10^{9}\right)\end{array}$ & $210 \pm 88.5$ & $200 \pm 97.4$ & 0.44 \\
\hline
\end{tabular}

As shown in Table 2, blood glucose, urea, creatinine, serum uric acid, HDL-cholesterol and white cell count at admission were significantly higher in patients who died than those who survived. Furthermore patients who died had significantly depressed level of consciousness, higher NIHSS, faster pulse rate and higher diastolic blood pressure than those who survived.

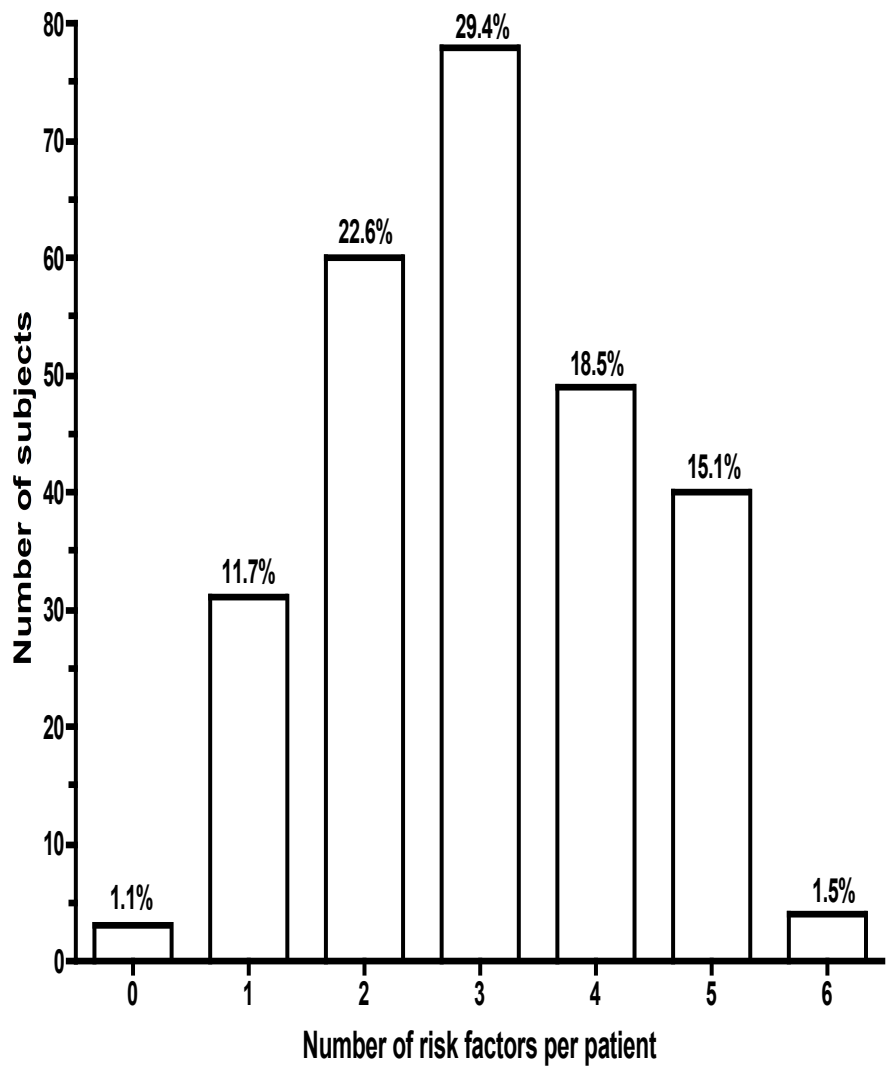

Figure 1 Graph showing the cumulative number of modifiable risk factors per patient.

A multivariate logistic regression analysis showed that the risk of death was significantly predicted by severity of stroke and hyperuricaemia (Table 3). Finally, among patients who were discharged a significant proportion severe functional limitation as depicted in Figure 2. 
Table 3 Univariate and multivariate logistic regression analysis of clinical and laboratory parameters associated with in-patient mortality after stroke.

\begin{tabular}{|c|c|c|c|c|}
\hline Variable & $\begin{array}{l}\text { Unadjusted odds } \\
\text { ratio }(95 \% \mathrm{CI})\end{array}$ & p-value & $\begin{array}{l}\text { Adjusted odds ratio } \\
(95 \% \mathrm{CI})\end{array}$ & p-value \\
\hline $\begin{array}{l}\text { NIHSS }^{1} \\
\quad \text { per unit increase }\end{array}$ & $1.31(1.20-1.42)$ & $<0.0001$ & $1.22(1.08-1.36)$ & 0.001 \\
\hline $\begin{array}{r}\text { Glasgow coma score } \\
\text { per unit increase }\end{array}$ & $0.61(0.53-0.71)$ & $<0.0001$ & $0.81(0.62-1.04)$ & 0.10 \\
\hline $\begin{array}{l}\text { Random blood sugar } \\
\text { per each } 1 \mathrm{mmol} \text { increase }\end{array}$ & $1.15(0.82-1.62)$ & 0.40 & - & - \\
\hline $\begin{array}{l}\text { White blood cell count } \\
\text { leukocytosis }{ }^{2} \\
\text { within normal range }\end{array}$ & $\begin{array}{l}3.55(1.62-7.75) \\
1.00\end{array}$ & 0.002 & $\begin{array}{l}1.99(0.50-7.87) \\
1.00\end{array}$ & 0.32 \\
\hline $\begin{array}{l}\text { Serum Urea concentration } \\
\quad>7 \mathrm{mmol} / 1 \\
\leq 7 \mathrm{mmol} / 1\end{array}$ & $\begin{array}{l}1.45(0.70-3.02) \\
1.00\end{array}$ & 0.32 & - & - \\
\hline $\begin{array}{l}\text { Serum creatinine concentration } \\
\quad>115 \mu \mathrm{mol} / 1 \\
\quad \leq 115 \mu \mathrm{mol} / 1\end{array}$ & $\begin{array}{l}2.02(0.99-4.09) \\
1.00\end{array}$ & 0.05 & $\begin{array}{l}1.40(0.34-5.76) \\
1.00\end{array}$ & 0.64 \\
\hline $\begin{array}{c}\text { Serum uric acid concentration } \\
\text { Elevated } \\
\text { Normal }\end{array}$ & $\begin{array}{l}1.15(1.06-1.25) \\
1.00\end{array}$ & 0.0008 & $\begin{array}{l}5.54(1.39-28.22) \\
1.00\end{array}$ & 0.02 \\
\hline
\end{tabular}

${ }^{1}$ NIHSS- National Institute of Health Stroke Scale used to assess severity of stroke.

${ }^{2}$ Leukocytosis defined as WBC count $>10 \times 10^{9}$.

3 Elevated serum uric acid defined as fasting serum uric concentration $>360 \mathrm{mmol} / 1$ for females and $>420 \mathrm{mmol} / 1$ for males.

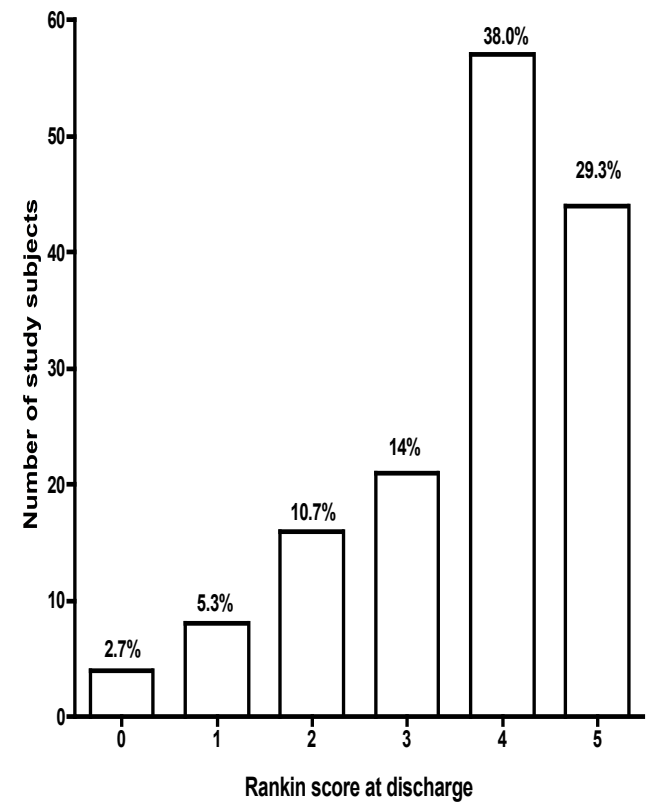

Figure 2 Graph showing the Rankin score of functional limitation among stroke patients on discharge from hospital.

\section{DISCUSSION}

Stroke is a preventable cardiovascular disorder with well-recognised risk factors. The identification and appropriate modification of these risk factors are the targets of both primary and secondary preventive strategies. ${ }^{12,14}$ The objective of this study was to describe the prevalence of the conventional risk factors, types and outcomes of stroke in Kumasi, Ghana. The main observations in the present study were the following: firstly, there was a high prevalence of hypertension $(85 \%)$ overall among stroke patients in Ghana. Secondly stroke patients had a median of at least three modifiable risk factors, which were not been managed prior to the onset of stroke. Thirdly there was a high in-patient mortality of $43.4 \%$ together with severe functional limitation among survivors upon discharge regardless of the type of stroke.

Overall the demographics, risk factor profile and outcomes of stroke in this study were comparable with other studies conducted in sub-Saharan Africa. Age is the strongest risk factor for both cerebral ischaemia and primary intracerebral haemorrhage. The incidence of stroke approximately doubles with each decade over the age of 55 years. ${ }^{15}$ 
The mean age of 64.6 years of the participants was higher than the 59.8 years previously reported about a decade ago in Accra, Ghana, ${ }^{16} 60.4$ years reported in Dakar, Senegal, ${ }^{17} 58$ years in a Gambian cohort, ${ }^{18} 56$ years in Kano, Nigeria, ${ }^{19} 55$ years in Maiduguri (northeastern Nigeria $)^{20}$ and 54 years in Ogun and Lagos states (South-western Nigeria) ${ }^{21}$ respectively.

The slightly older age of stroke patients in this study than those reported in elsewhere in sub-Saharan Africa is probably a reflection of the gradually improving socio-economic status of Ghanaians and other developing countries that are in a demographic transition. It is important to note that these cited studies were conducted either in the late 1990's or early 2000's. Indeed a recent study conducted in Port Harcourt, Nigeria and published in 2009 for instance showed the mean age of stroke patients was 62.6 years. $^{22}$

Male gender is a risk factor for stroke overall, however due to their greater life expectancy and the greater importance of age as a risk factor, more women will suffer stroke during their lifetime. This observation was reflected in this study, as there was a preponderance of females over males with a ratio of 1.3:1.0, which was similarly observed in the Port Harcourt study ${ }^{22}$ where the female to male ratio was $1.2: 1.0$. However in a previous Ghanaian study, there has been a tendency for a slight male predominance. ${ }^{16}$

Of the modifiable risk factors of stroke, systemic arterial hypertension remains the most potent risk factor for stroke with a 7-fold relative risk compared with normotensives. $^{23}$ Studies conducted in sub-Saharan Africa has consistently shown the importance of hypertension as a risk factor for stroke ${ }^{19,20,24}$ and we show that although $85 \%$ of subjects were hypertensive, only $59 \%$ were aware of the presence of hypertension with $35 \%$ of hypertensive patients admitting to compliance to their medications prior to the onset of stroke. It is also interesting that non-compliance to therapy was largely attributed to the frequent use of herbal remedies.

Thus the escalation of stroke in developing countries may be attenuated by improved screening of the adult population for the presence of vascular risk factors through strengthening of public health educational programmes. Importantly, we also note that most patients had a median of 3 risk factors which required concurrent management, thus primary physicians involved in the care of patients should actively embark on a screening programme to identify all possible risk factors in their patients in order to maximise the benefit of risk factor modification.
Using the Siriraj Stroke Scale (SSS) the frequency of ischaemic and haemorrhagic varieties of stroke in this study were $43 \%$ and $39 \%$ respectively in Kumasi, with the scoring system unable to classify the remaining $18 \%$ of cases. A previous study conducted in Accra, Ghana by Obajimi et al. showed the prevalence of CT scan confirmed ischaemic and haemorrhagic strokes to be $47.1 \%$ and $52.9 \%{ }^{16}$ respectively as has also been shown in Nigeria where Ogun et al. found that $49 \%$ of strokes in the Ogun state were accounted for by the ischaemic variety with $45 \%$ being haemorrhagic. ${ }^{25}$

The use of a clinical scoring system for classifying stroke may have compromised the quality our analyses, however the SSS has been validated in resource - limited settings and has been shown to be accurate in classifying strokes. Its overall predictive accuracy compared to the gold standard of CT scan was found to be $90 \%$ in Bangkok, Thailand, ${ }^{11} 80 \%$ in Southwest Nigeria ${ }^{21}$ although one retrospective study reported a low predictive accuracy of $54 \%$ in the Ogun state. ${ }^{26}$ In this study we found the overall predictive accuracy of the SSS to be $100 \%$ with excellent sensitivity and specificity for cerebral infarction and a somewhat reduced sensitivity and specificity for intracerebral haemorrhage.

The high mortality of stroke in sub-Sahara African studies is indicative of our unpreparedness for the stroke epidemic. In-patient case fatality rate in our series was $43.4 \%$. At the Lagos University Teaching Hospital case fatality of stroke was $26 \%$ at 7 days, $41.2 \%$ at 30 days and $86 \%$ at 6 months of incident stroke $^{27,28}$ and this was similar to that in the Ogun state of $28 \%, 40 \%$ and $46 \%$ respectively. ${ }^{25}$ Similarly $1-$ month mortality after stroke was $38 \%$ in Dakar (Senegal), ${ }^{17} 27 \%$ in the Gambia, ${ }^{18}$ and $29.3 \%$ in Mauritania. ${ }^{29}$ Indeed it is now believed that two-thirds of stroke mortality world-wide occur in developing countries ${ }^{30,31}$ and is largely the result of inadequate infrastructure and delayed presentation of patients to health centres for management.

Even though $60 \%$ of stroke patients presented within 24 hours of ictus, a significant proportion had severe strokes, which undoubtedly impacted on stroke outcomes. In a multivariate logistic regression, death after stroke in this cohort was independently associated with the severity of stroke and hyperuricaemia at presentation on adjusted analysis (Table 3 ). The observed association between hyperuricaemia and risk of death is particularly interesting because there is ongoing debate on whether uric acid is protective ${ }^{32}$ or has adverse prognostic consequences ${ }^{33,34}$ after a stroke with our data in support of the later hypothesis. 
Further studies are required to explore the prognostic significance of uric acid in stroke within the African context.

\section{CONCLUSION}

In conclusion, our study shows that stroke is associated with unacceptably high in-patient mortality and patients have multiple risk factors requiring modification. Taken together the most cost-effective approach for the management of stroke in sub-Saharan Africa would be improved public health education directed at better awareness of risk factors and their management to prevent strokes while making concerted efforts at setting up stroke units to improve in-patient care and rehabilitation.

\section{REFERENCES}

1. Mathers CD, Loncar D: Updated projections of global mortality and burden of disease, 2002-2030: data sources, methods and results. Evidence and information for Policy. Geneva, World Health Organization, 2005.

2. Feigin VL, Lawes CM, Bennett DA, Barker-Collo SL, Parag V: Worldwide stroke incidence and early case fatality reported in 56 population-based studies: a systematic review. Lancet Neurol. 2009; 8(4):355-69.

3. Rosamond W, Flegal K, Furie K, Go Alan, Greenlund $\mathrm{K}$ et al. Heart disease and stroke statistics2008 update: a report from the American Heart Association Statistics Committee and Stroke Statistics Subcommittee. Circulation 2008; 117:e25146.

4. WHO STEPS Stroke Manual: the WHO STEPwise approach to stroke surveillance/ noncommunicable diseases and mental health. World Health Organisation 2005. NLM classification: WT 355.

5. Annual Report of Komfo Anokye Teaching Hospital, 2006.

6. World Health Organisation (1978). Cerebrovascular Disorders (Offset Publications). Geneva: World Health Organisation ISBN 9241700432.

7. Whitworth JA, for the World Health Organisation, International Society of Hypertension Writing Group. 2003 World Health Organisation (WHO)/ International Society of Hypertension (ISH) statement on management of hypertension. J Hypertens. 2003; 21:1983-1992.

8. Alberti KG, Zimmet PZ. Definition, diagnosis and classification of diabetes mellitus and its complications, part 1: diagnosis and classification of diabetes mellitus provisional report of a WHO consultation. Diabet Med. 1998; 15: 539 -553.
9. Strategies for the prevention of coronary heart disease: a policy statement of the European Atherosclerosis Society. Eur Heart J. 1987;8: 77-88.

10. Van der Sande MAB, Walraven GEL, Milligan PJM, Banya WAS, Ceesay SM, Nyan OA, McAdam KPWJ. Family history: an opportunity for early interventions and improved control of hypertension, obesity and diabetes. Bulletin of the World Health Organisation. 2001; 79: 321-328.

11. Poungvarin N, Viriyavejakul A, Komontri C. Siriraj stroke score and validation study to distinguish supratentorial intracerebral haemorrhage from infarction. BMJ. 1991; 302:1565-1567.

12. Goldstein LB, Adams R, Becker K, Furberg CD, Gorelick PB, Hademenos G, Hill M, Howard G, Howard VJ, Jacobs B, Levine SR, Mosca L, Sacco RL, Sherman DG, Wolf PA, del Zoppo GJ: Primary Prevention of Ischaemic Stroke: a statement for healthcare professionals from the Stroke Council of the American Heart Association. Circulation 2001, 103(I):163-182.

13. Sacco RL, Wolf PA, Gorelick PB: Risk factors and their management for stroke prevention: outlook for 1999 and beyond. Neurology 1999, 53(7 suppl 4):S 15-S24.

14. Wolf PA, Clagett GP, Easton JD, Goldstein LB, Gorelick PB, Kelly-Hayes M, Sacco RL, Whisnaut JP: Preventing ischaemic stroke in patients with prior stroke and transient ischaemic attack. A statement for healthcare professionals from the Stroke Council of the American Heart Association. Stroke 1999,30:1991-1994.

15. Wolfe CDA. The impact of stroke. British Medical Bulletin. 2000;56:275-286.

16. Obajimi MO, Nyame PK, Jumah KB, Wiredu EK. Computed tomographic patterns of intracranial infarcts in Ghanaians. West Afr J Med. 2002 AprJun; 21(2):121-3.

17. Sangui E, M'Baye PS, Dubecq C, Fall KB, Niang $\mathrm{A}$, et al. Ischaemic and haemorrhagic strokes in Dakar, Senegal. A hospital-based study. Stroke. 2005; 36:1844-1847.

18. Walker R, Rolfe M, Kelly P, George M, James O. Mortality and recovery after stroke in the Gambia. Stroke. 2003; 34:1604-1609.

19. Karaye KM, Nashabaru I, Fika GM, Ibrahim DA, Maiyaki BM, Ishaq NA, Abubakar LY, Nalado AM, Hassan M, Bello AK, Yusif SM. Prevalence of traditional cardiovascular risk factors among Nigerians with stroke. Cardiovasc J Afr. 2007 Sep-Oct; 18(5):290-4.

20. Bwala SA. Stroke in a Sub-Saharan Nigerian Hospital- a retrospective study. Trop Doct 1989; 19(1): 11-14. 
21. Kolapo KO, Ogun SA, Danesi MA, Osalusi BS, Odusote KA. Validation study of the Siriraj stroke score in African Nigerians and evaluation of the discriminant values of its parameters: a preliminary prospective CT scan study. Stroke. 2006; 37:1997-2000.

22. Onwuchewa A, Bellgam H, Asekomeh G. Stroke at the university of Port Harcourt teaching hospital, river state, Nigeria. Trop Doct. 2009 Jul;39(3):150-152.

23. Collins R and Mac Mahon S. Blood pressure, antihypertensive drug treatment and the risks of stroke and of coronary heart disease. British Medical Bulletin. 1994;50: 272-298.

24. Zabsonre P, Yameogo A, Millogo A, et al. Risk and severity factors in cerebrovascular accidents in West African Blacks of Burkina Faso. Med Trop 1997; 57(2): 147-152.

25. Ogun SA, Ojini FI, Ogungbo B, Kolapo KO, Danesi MA. Stroke in South West Nigeria: A 10year review. Stroke. 2005;36:1120-1122.

26. Ogun SA, Oluwole O, Fatade B, Ojini F, Odusote KA, Ogunseyinde AO. Accuracy of the Siriraj stroke score in differentiating cerebral haemorrhage and infarction in African Nigerians. African J Neurological Sci. 2001; 20:21-26.
27. Ogun SA. Acute stroke mortality at Lagos University Teaching Hospital. Nig Q J Hosp Med. 2000; 10:8-10.

28. Ojini FI, Ogun SA, Danesi MA. Thirty days case fatality of stroke at LUTH. Nig $Q J$ Hosp Med. 2004: 14:64-66.

29. Diagana M, Traore H, Bssima A, Druet-Cabanac M, Preux PM, Dumas M. Apport de la tomodensitométrie dans le diagnostic des accidents vasculaires cérébraux à Nouakchott, Mauritanie. Med Trop.2002; 62:145-149.

30. Sagui E. Stroke in Sub- Saharan Africa. Med Trop (Mars). 2007; 67 (6): 596-600.

31. Cannor MD, Walker R, Modi G, Warlow CP. Burden of stroke in black populations in sub-saharan Africa. Lancet Neurol. 2007 Jun;6(6): 479.

32. Chamorro A, Obach V, Cervera A, Revilla M, Deulofeu R, Aponte JH. Prognostic significance of uric acid concentration in patients with acute ischaemic stroke. Stroke 2002 Apr;33(4):1048-52.

33. Weir CJ, Muir SW, Walters MR, Lees KR. Serum urate as an independent predictor of poor outcome and future vascular events after acute stroke. Stroke 2003; 34: 1951-1956.

34. Karagiannis A, Mikhailidis DP, Tziomalos K, Sileili M, et al. Serum uric acid as an independent predictor of early death after acute stroke. Circ $J$ 2007; 71: 1120-1127. 